\title{
GRAVITY VARIATIONS AND RECENT GEODYNAMICS OF THE SOUTH-WESTERN PART OF THE BAIKAL REGION
}

\author{
V. Yu. Timofeev ${ }^{1}$, Ye. N. Kalish ${ }^{2}$, Yu. F. Stus' ${ }^{2}$, D. G. Ardyukov ${ }^{1}$, \\ G. P. Arnautov', M. G. Smirnov' ${ }^{2}$, A. V. Timofeev', D. A. Nosov ${ }^{2}$, \\ I. S. Sizikov², E. V. Boiko ${ }^{1}$, E. I. Gribanova ${ }^{3}$
}

${ }^{1}$ A.A. Trofimuk Institute of Petroleum Geology and Geophysics SB RAS, Novosibirsk, Russia

${ }^{2}$ Institute of Automation and Electrometry SB RAS, Novosibirsk, Russia

${ }^{3}$ Siberian Division of Geophysic Survey SB RAS, Novosibirsk, Russia

\begin{abstract}
Modern methods for determination of gravity values make it possible to obtain measurements with the accuracy up

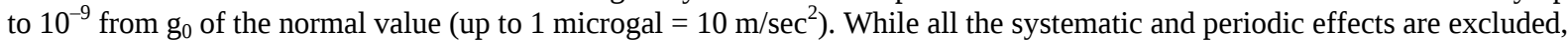
a question is raised about stability of the gravity field of the Earth over time. Changes of the altitude (the Earth's radius) with time can be estimated with an accuracy of $0.1 \mathrm{~mm}$ by modern space geodetic techniques, such as VLBI method. Our experiments for evaluation of stability of the gravity values over the past decades are based on the data obtained by Russian and foreign observatories using absolute ballistic laser gravimeters. The results put a limit of $10^{-10}$ per year to changes of the Earth's radius. These estimations can be useful for testing hypotheses in tectonics.

Measurements of non-tidal variations of gravity $(\Delta \mathrm{g})$, which were obtained from 1992 to 2012 at the Talaya seismic station (located in the south-western part of the Baikal region), are interpreted together with GPS observation data. At the Talaya seismic station, the linear component of gravity variations corresponds to changes in the elevation of this site. The correlation coefficient is close to the normal value of the vertical gradient of gravity. At this site, coseismic gravity variations at the time of the Kultuk earthquake (27 August 2008, Mw=6.3) were caused by a combined effect of the change of the site's elevation and deformation of the crust. Our estimations of the coseismic effects are consistent with results obtained by modeling based on the available seismic data.
\end{abstract}

Key words: monitoring of gravity variations, changes in the Earth's radius, rift zone, GPS-monitoring, earthquake.

Recommended by V.A. San'kov

Citation: Timofeev V.Yu., Kalish Ye.N., Stus' Yu.F., Ardyukov D.G., Arnautov G.P., Smirnov M.G., Timofeev A.V., Nosov D.A., Sizikov I.S., Boiko E.V., Gribanova E.I. 2013. Gravity variations and recent geodynamics of the south-western part of Baikal region. Geodynamics \& Tectonophysics 4 (2), 119-134. doi:10.5800/GT-20134-2-0094.

\section{ВАРИАЦИИ СИЛЫ ТЯЖЕСТИ И СОВРЕМЕННАЯ ГЕОДИНАМИКА ЮГО-ЗАПАДНОЙ ЧАСТИ БАЙКАЛЬСКОГО РЕГИОНА}

\author{
В. Ю. Тимофеев ${ }^{1}$, Е. Н. Калиш ${ }^{2}$, Ю. Ф. Стусь ${ }^{2}$, Д. Г. Ардюков ${ }^{1}$, \\ Г. П. Арнаутов ${ }^{2}$, М. Г. Смирнов ${ }^{2}$, А. В. Тимофеев ${ }^{1}$, Д. А. Носов ${ }^{2}$, \\ И. С. Сизиков ${ }^{2}$, Е. В. Бойко ${ }^{1}$, Е. И. Грибанова ${ }^{3}$ \\ ${ }^{1}$ Институт нефтегазовой геологии и геофизики им. А.А. Трофимука СО РАН, Новосибирск, Россия \\ ${ }^{2}$ Институт автоматики и электрометрии СО РАН, Новосибирск, Россия \\ ${ }^{3}$ Сибирский филиал Геофизической службы СО РАН, Новосибирск, Россия
}


Аннотация: Современные методы определения значения силы тяжести позволяют проводить измерения с точностью до $10^{-9}$ от g нормального значения (до 1 микрогала = $10 \mathrm{Hm} / \mathrm{c}^{2}$ ). При этом исключаются все систематические и периодические эффекты и возникает вопрос о стабильности поля силы тяжести Земли во времени. Оценить изменения высоты (радиуса Земли) во времени с точностью до 0.1 мм позволяют современные методы космической геодезии (VLBI метод). Экспериментальные оценки стабильности значения силы тяжести за последние десятилетия сделаны по материалам отечественных и зарубежных обсерваторий, использующих абсолютные лазерные баллистические гравиметры. Полученные результаты ограничивают изменение радиуса Земли значением $10^{-10}$ в год. Эти оценки можно использовать для тестирования тектонических гипотез.

Результаты измерений неприливных вариаций ускорения силы тяжести $\Delta \mathrm{g}$, проведенных в $1992-2012$ гг. на сейсмостанции «Талая» (юго-западная часть Байкальского региона), интерпретируются совместно с данными GPSнаблюдений. Линейная составляющая вариации силы тяжести на станции Талая соответствует изменениям высоты пункта. Коэффициент корреляции близок к нормальному значению вертикального градиента силы тяжести. Косейсмические вариации силы тяжести на этом пункте в эпоху Култукского землетрясения (27.08.2008 г., Мw=6.3) вызваны комплексным эффектом изменения высоты пункта и деформации земной коры. Оценки косейсмических эффектов соответствуют результатам моделирования на основе сейсмологических данных.

Ключевые слова: мониторинг вариаций силы тяжести, изменение радиуса Земли, рифтовая зона, GPS-наблюдения, землетрясения.

\section{1. ВВЕДЕНИЕ}

Гравиметрические наблюдения являются важной частью комплексных геофизических измерений. Высокоточные измерения позволяют оценить стабильность значения силы тяжести и значения высоты пункта во времени - рассмотреть возможность изменения радиуса Земли, т.е. тестировать тектонические гипотезы о пульсирующей или расширяющейся Земле [Elhiny et al., 1978; Kukol, 1987]. Определение скорости постледниковых поднятий методами геодезии и гравиметрии позволяет дать оценки вязким параметрам геологической среды. Вместе с тем физически очевидная связь вертикальных смещений и изменений силы тяжести до последнего времени не находила ясного отражения в экспериментальных результатах, полученных в зонах высокой сейсмичности. В последние десятилетия с повышением точности гравиметрических измерений и появлением методов космической геодезии появилась реальная возможность прояснить этот вопрос. Важным дополнением этих работ являются измерения локальной деформации поверхности. Наиболее интересные результаты могут быть получены при проведении многолетних наблюдений, включая периоды сильных землетрясений со значительными косейсмическими изменениями. При этом, помимо данных о долговременных региональных процессах, они дают дополнительную информацию о положении и глубине разрыва при землетрясении, о мощности земной коры, охваченной деформациями. Исследования проводились в Байкальской рифтовой зоне (БРЗ), где наблюдается активный сейсмический процесс и регистрируется более 2000 землетрясений в год, при этом в центре БРЗ в основном регистрируются землетрясения со значительной вертикальной компонентой смещений. Измерения проводились отечественным аб- солютным гравиметром ГАБЛ [Arnautov et al., 1994], геодезическими двухчастотными приемниками TRIMBLE-4700, лазерными и штанговыми деформографами и приливными наклономерами.

\section{2. ОЦЕНКА СТАБИЛЬНОСТИ СИЛЫ ТЯЖЕСТИ ЗЕМЛИ}

Для описания измерений силы тяжести g во времени можно воспользоваться простой моделью:

$g(r, t)=g(r)+g_{e}(r, t)+\zeta$

где $\mathrm{r}$ - вектор положения, $\mathrm{t}$ - время и $\zeta$ - погрешность измерений.

Как известно, сезонная компонента вносит значимый вклад в изменения вертикальных смещений и силы тяжести на пункте. Изучение с помощью GPS-приемников, SG гравиметра и абсолютного гравиметра FG5 сезонной составляющей и тренда на итальянской обсерватории (Medicina, 1992-2002) показало, что отношение вертикальных смещений и g дает значение коэффициента -3 мм/мкгал, т.е. соответствует нормальному вертикальному градиенту $\gamma$ силы тяжести (рис. 1).

Сезонные вариации, связанные с изменением уровня грунтовых вод по данным французской обсерватории (Strasbourg, гравиметр FG5, 1997-2004) достигают 5 микрогал, а в целом по сети европейских станций со стационарными криогенными гравиметрами амплитуда сезонных вариаций составляет 3-8 микрогал [Hinderer, Crossley, 2006]. Влияние гидрологических факторов сложно рассчитать, но их можно минимизировать, при размещении постамента для измерений на коренных породах [Tsuboi, 1982].

Следующие зависимые от времени факторы - это 


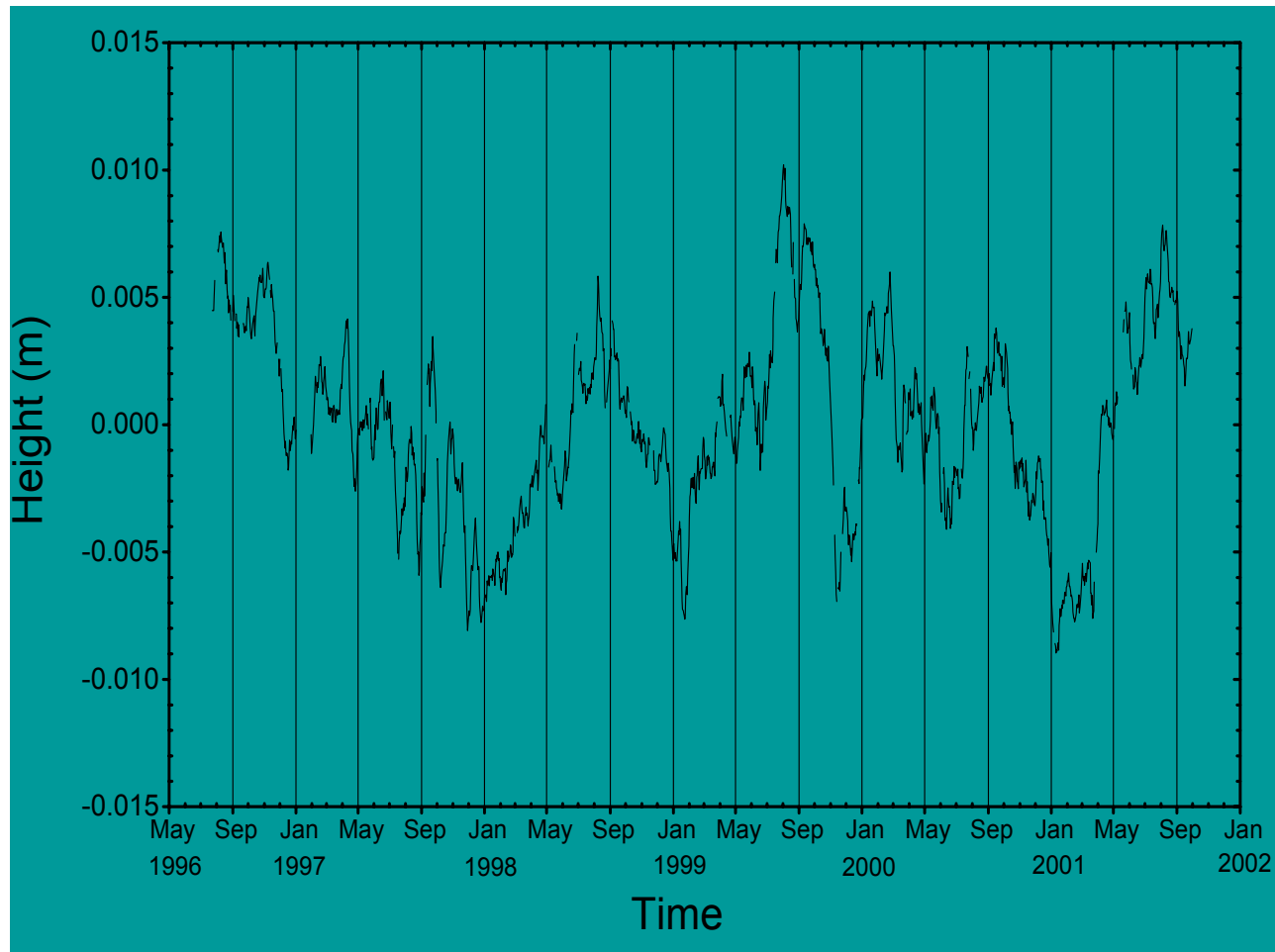

b

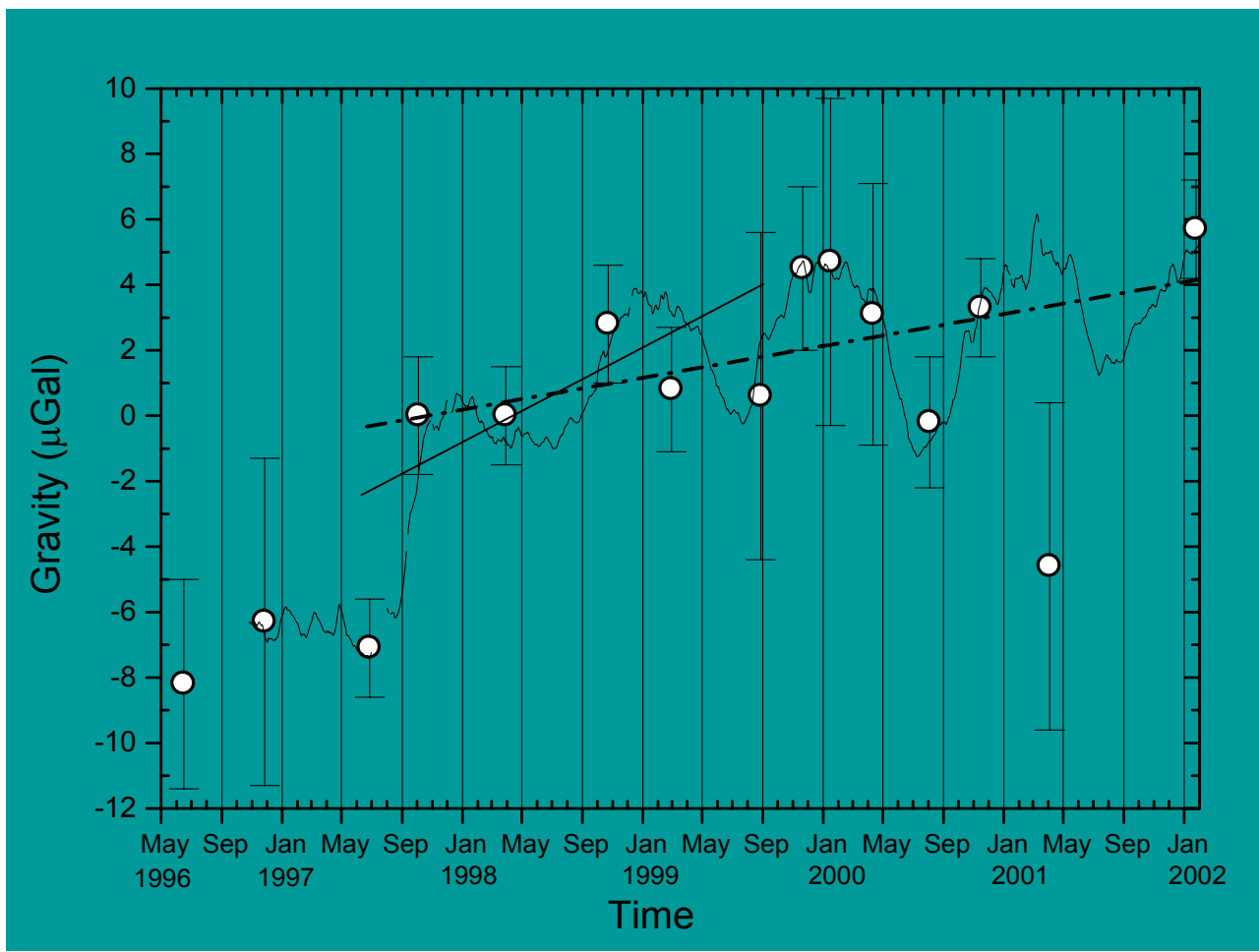

Рис. 1. Результаты измерений вертикальных смещений (в метрах) с помощью GPS-приемников (a) и силы тяжести (измерения SG гравиметром на эффекте сверхпроводимости - сплошная линия и абсолютным гравиметром FG5) за 6 лет на итальянской обсерватории Medicina (05.1996-01.2002) в микрогалах (b).

Система СИ: ускорение силы тяжести, нормальное значение $\mathrm{g}_{0} \approx 9.8 \mathrm{~m} / \mathrm{c}^{2}, 1 \cdot 10^{-9} \mathrm{~m} / \mathrm{c}^{2}=1 \mathrm{Hм} / \mathrm{c}^{2}$. Внесистемные единицы: 1 см/с ${ }^{2}=1$ гал; $10^{-3}$ гал = 1 миллигал $(\mathrm{mGal}) ; 10^{-6}$ гал $=1$ микрогал $(\mu \mathrm{Gal}) ; 10^{-9}$ гал $=1$ наногал; 1 микрогал $=10$ нм/ ${ }^{2} \approx 10^{-9} \mathrm{~g}_{0}$, т.е. наноуровень эффектов.

Fig. 1. Vertical displacement measurements (in meters) by GPS receivers (a) and gravity measurements by an SG gravity meter based on the effect of superconductivity (shown as the solid line) and an FG5 absolute gravimeter (in microgal) for a period of six years, from May 1996 to January 2002; the surveys were conducted at the Medicina observatory, Italy.

SI system: gravity acceleration, the normal value $\mathrm{g}_{0} \approx 9.8 \mathrm{mps}^{2}, 1 \cdot 10^{-9} \mathrm{mps}^{2}=1 \mathrm{nmps}^{2}$. Units out of the system: $1 \mathrm{cmps}^{2}=1 \mathrm{gal}, 10^{-3}$ gal $=1 \mathrm{mil}-$ ligal (mGal); $10^{-6} \mathrm{gal}=1$ microgal $(\mu \mathrm{Gal}) ; 10^{-9} \mathrm{gal}=1$ nanogal. 1 microgal $=10 \mathrm{nmps}^{2} \approx 10^{-9} \mathrm{~g}_{0}$, i.e. nanolevel of effects. 


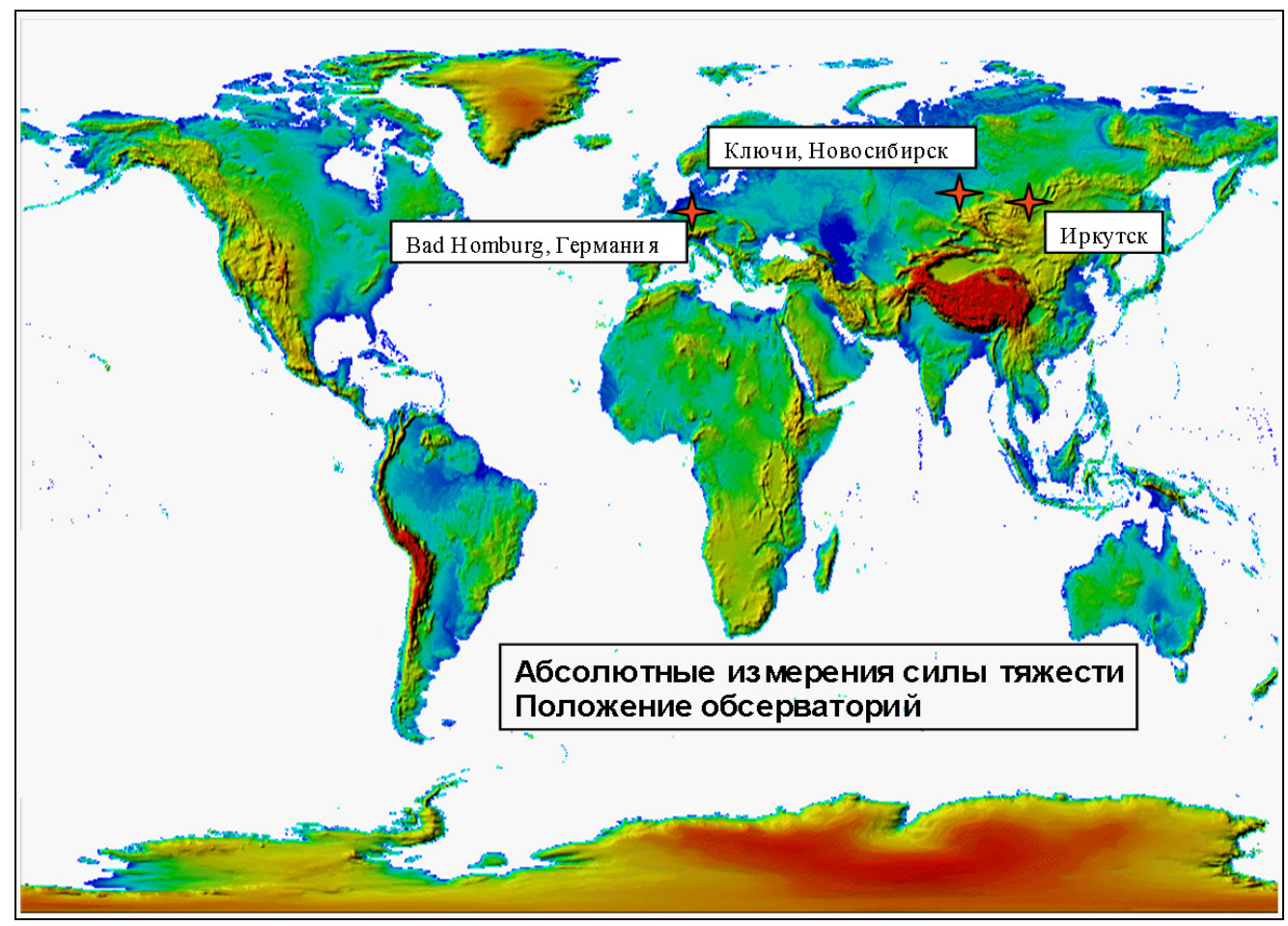

Рис. 2. Положение комплексных геофизических обсерваторий.

Fig. 2. Locations of integrated geophysical observatories.

эффекты земного прилива и полюса. Они рассчитываются достаточно точно. Так, для определения приливных параметров и выбора модели были проведены измерения с гравиметрами ЛаКоста-Ромберга по широтному профилю, простирающемуся от севера Франции до острова Сахалин [Ducarme et al., 2008]. Поправки за движения полюса Земли вводятся с использованием данных международного центра по вращению Земли, полученных экспериментально.

Изучение вариаций g во времени требует оценки стабильности значения силы тяжести Земли и ее высот. С учетом наличия скорости при линейной связи получаем следующее соотношение:

$g(r, t)=g^{\prime} \cdot\left(t-t_{0}\right)+g\left(r, t_{0}\right)+g_{e}(r, t)+\varepsilon$,

где g' - скорость изменений и $\mathrm{t}_{0}-$ начальное время.

Связь вариаций g и высоты Z без учета деформации среды можно описать как:

$\Delta g(t)=\gamma \cdot \Delta \mathrm{Z}(\mathrm{t})+\varepsilon$

где $\gamma$ - вертикальный градиент g и $\Delta \mathrm{Z}(\mathrm{t})$ - изменение высоты пункта.

Для высот сложно говорить о глобальных вариациях, так как мировая система измерений находится в развитии, практически каждые пять лет с появлением новых станций происходит небольшое изменение глобальной референц-системы [Altamimi et al., 2007] и уточнение геофизических моделей, используемых при построении и развитии глобальной отсчетной основы [Kaftan, Tsyba, 2009]. По оценкам отдельных авторов, вариации незначительно превышают ошибку; например, из обобщения по сети VLBI получена оценка 0.11 0.05 мм/год [Kolomiets et al., 2010].

Какова величина скорости g' в соотношении (2)? Рассмотрим экспериментальные результаты, полученные на обсерваториях комплексных геофизических измерений - методами GPS-геодезии и абсолютной гравиметрии. Мониторинговые измерения с гравиметром ГАБЛ начаты на обсерватории Ключи (Новосибирск) в 1975-1977 гг. (рис. 2). Абсолютный лазерный баллистический гравиметр ГАБЛ неоднократно участвовал в международных сверках приборов этого класса [Robertson et al., 2001].

GPS-наблюдения на обсерватории Ключи начаты в 2000 г. Полученные за период 1977-2009 гг. на обсерватории Ключи значения силы тяжести приведены на рис. 3. Вариации на периоде наблюдений не превысили ошибку повторных измерений (0.5-2.0 мкгал). Стабильность значения силы тяжести за период 19772009 гг. составила 0.06 мкгал/ год.

Измерения с гравиметром ГАБЛ на астроплощадке в г. Иркутске проводились с 1995 г. с момента организации GPS наблюдений на пункте (рис. 3). Результаты измерений (микрогальная часть значения) с 1995 г. по 2006 г. приведены на рис. 4. Отклонение от среднего значения не превышает 3 мкгал. Стабильность 
Time series for IRKT.
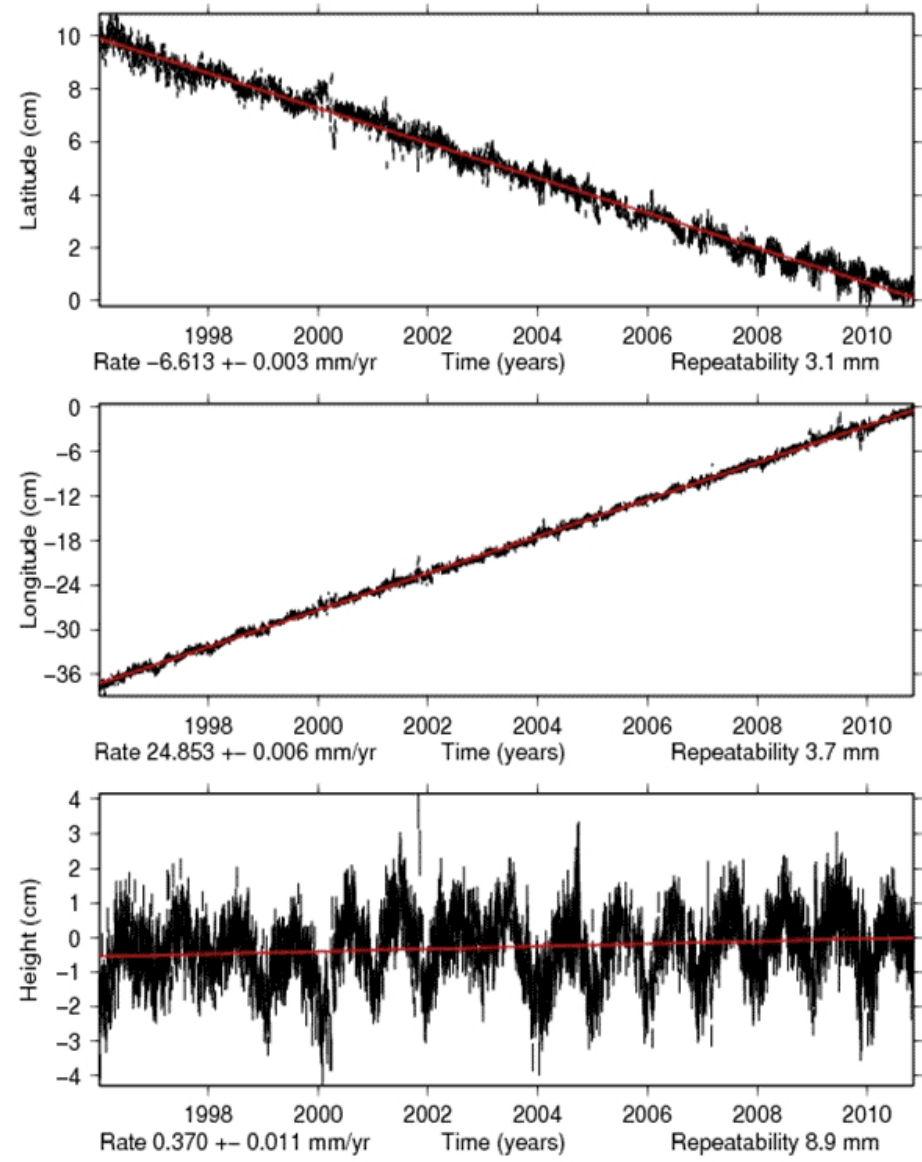

Time series for IRKJ.
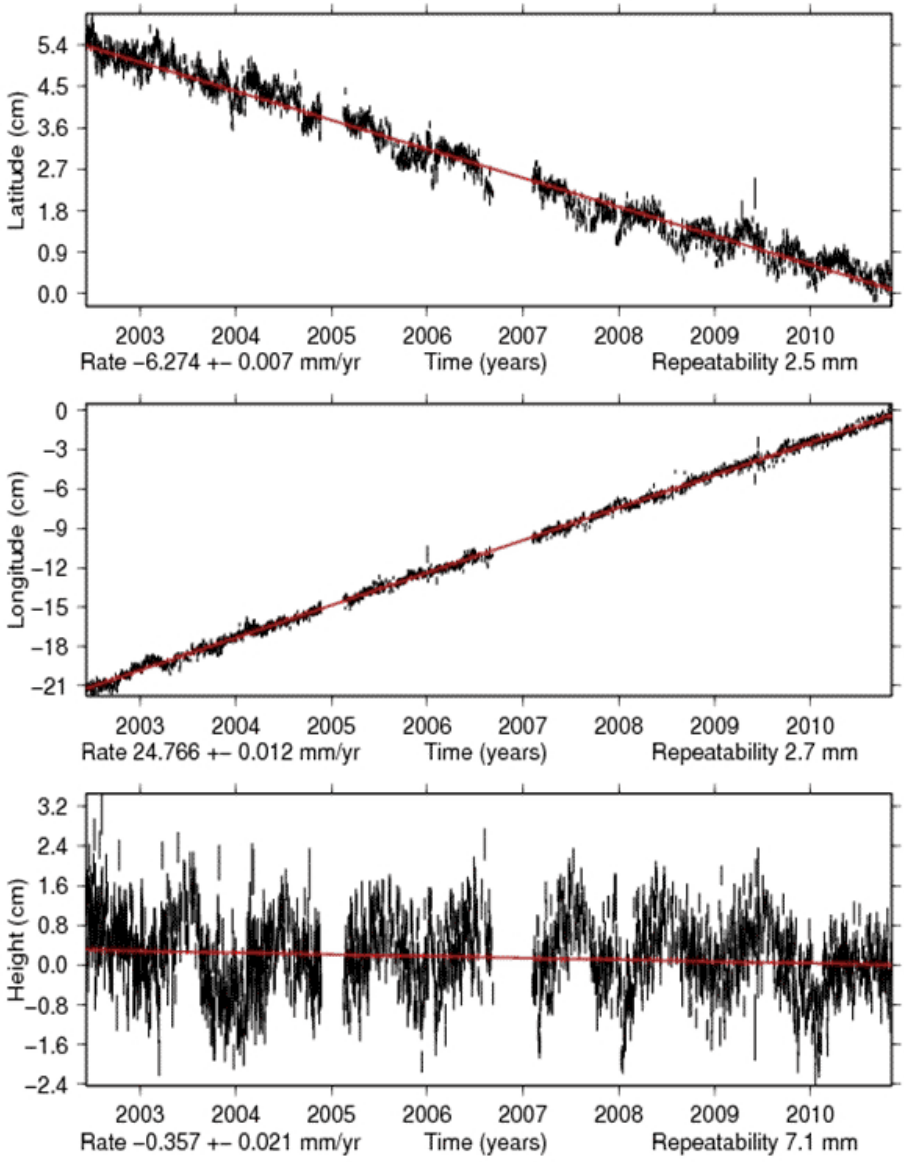

Рис. 3. Астрономическая обсерватория Иркутск, данные GPS-измерений в двух точках за период 1995-2010 гг. и $2002-$ 2010 гг.

Геоцентрическое решение, скорости смещений С-Ю, В-3 и вертикальные в сантиметрах. Сезонная компонента на вертикальной компоненте связана с климатическими вариациями, скорости $+0.370 \pm 0.011$ и $-0.357 \pm 0.021$ мм/год.

Fig. 3. The Irkutsk Astronomical Observatory; GPS measurements at two points for periods from 1995 to 2010 and from 2002 to 2010.

The geocentric solution; S-N, E-W and vertical displacements are given in centimetres. The seasonal component to the vertical component is associated with climatic variations; velocities of $+0.370 \pm 0.011$ and $-0.357 \pm 0.021 \mathrm{~mm}$ per year.

значения за период 1995-2006 гг. составила 0.27 мкгал/год.

В Европе по данным германской обсерватории (Bad Homburg, 1994-2004 гг. использована группа абсолютных гравиметров FG5) стабильность значения g лежит в пределах ошибки измерений 2 мкгал [Hinderer, Crossley, 2006], т.е. уровень вариаций, или стабильность, составляет 0.2 мкгал/год (рис. 5).

В итоге приходим к выводу, что по экспериментальным данным стабильность значения силы тяжести Земли следует оценить как 0.2 мкгал. На современном этапе возможный эффект глобального изменения g и высоты можно ограничить $10^{-10}$ в год от нормального значения. Даже для десятилетней серии измерений эффект от возможных глобальных вариаций не превысит погрешности измерений.

\section{3. МОНИТОРИНГОВЫЕ ИЗМЕРЕНИЯ В ОБСЕРВАТОРИИ ТАЛАЯ}

Первые измерения с гравиметром ГАБЛ в БРЗ проведены осенью 1992 г. на сейсмостанции Талая (TLY, $\left.51.68^{\circ} \mathrm{N}, 103.64^{\circ} \mathrm{E}\right)$, расположенной в 7 км от югозападного берега озера Байкал и в 3 км южнее Главного Саянского разлома, являющегося границей Сибирской платформы и БР3 (рис. 6). Здание станции расположено в узкой горной долине, дно ее заполнено моренными отложениями мощностью от 0 до 3 м, лежащими на коренных породах. Для проведения гравиметрических и сейсмологических измерений в 1987 г. в здании построен подвал с двумя постаментами, основания постаментов практически достигают коренных пород долины. В 30 м от здания расположена 90- 
a

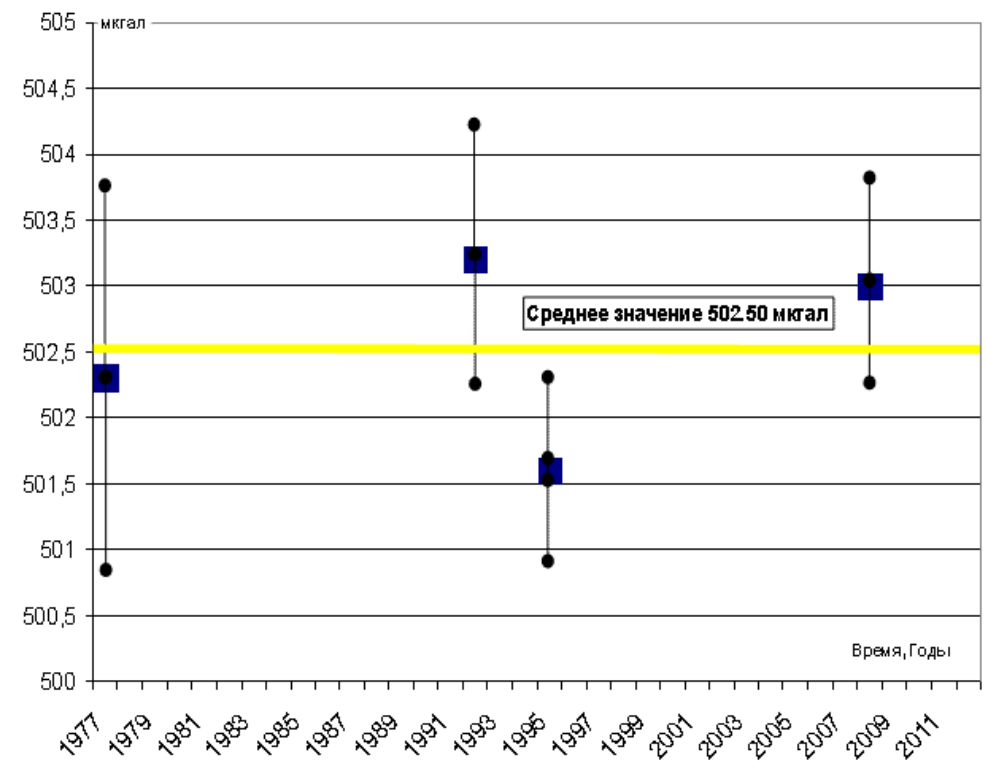

$b$

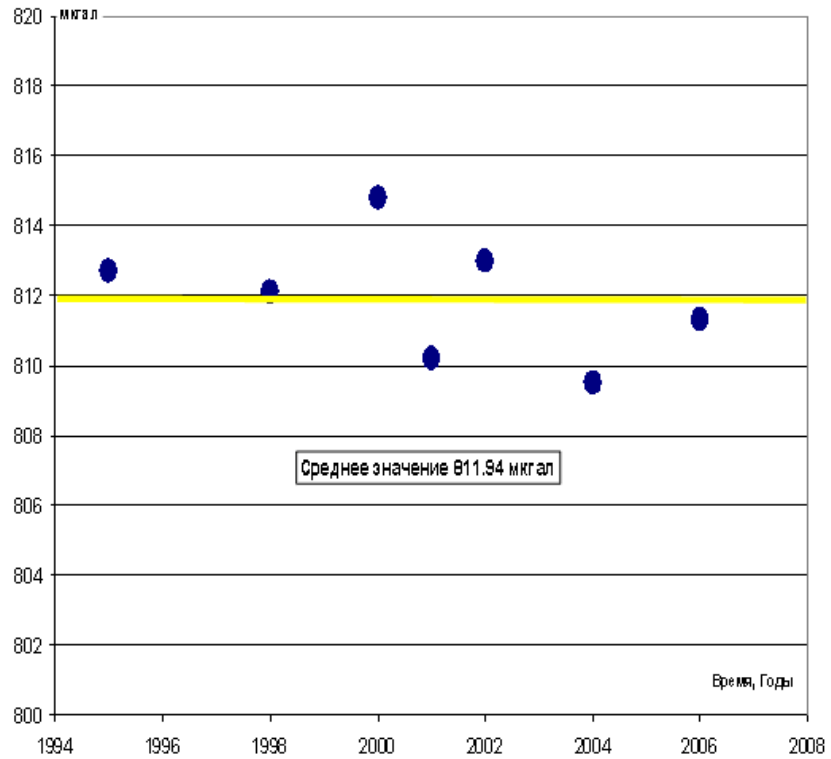

Рис. 4. Результаты гравиметрических измерений на сибирских станциях (последние три цифры - абсолютное значение в микрогалах).

Время - годы, значения в микрогалах. $a$ - обсерватория Ключи, стабильность значения силы тяжести за период 1977-2009 гг., 1.8 мкгал/32 года = 0.06 мкгал/год; $b$ - астрономическая площадка (г. Иркутск), стабильность значения за период 1995-2006 гг. - 3 мкгал/11 лет $=0.27$ мкгал/ год.

Fig. 4. Results of gravimetric measurements at stations in Siberia, Russia (the last three digits of the absolute value are given in microgals).

Time is given in years; values are given in microgals. $a$ - the Klyuchi observatory, the stability of gravity values for the period from 1977 to 2009 -1.8 microgals/32 years $=0.06$ microgals per year; $b$ - the astronomical site in Irkutsk, the stability of values for the period from 1995 to $2006-$

3 microgals $/ 11$ years $=0.27$ microgals per year.

метровая штольня, оборудованная для проведения сейсмологических и геофизических измерений. На другой стороне долины в 100 м от здания в коренных породах пробурена 100-метровая скважина, на которой с 1993 г. проводятся замеры уровня воды. По условиям видимости спутников для установки GPS-пункта выбрана открытая площадка в 300 м выше по долине, постамент со штангой установлен в 1999 г., а измерения проводятся с весны 2000 г. Гравиметрические измерения проводятся ежегодно, а в отдельные периоды несколько раз в год.

На основании результатов гравиметрических наблюдений в Новосибирской области (ст. Ключи) и в г. Иркутске можно заключить, что наблюдаемые на пункте «Талая» вариации $\Delta \mathrm{g}$ являются региональными и связаны с сейсмическими процессами в БРЗ. При этом основными причинами изменений $\Delta \mathrm{g}$ могут быть две: изменения плотности земной коры в районе наблюдений и вариации высоты пункта наблюдений.

Результаты гравиметрического мониторинга на сейсмостанции «Талая» и в г. Иркутске показаны на рис. 7. В эти результаты внесены поправки (согласно рекомендациям Международной гравиметрической комиссии), учитывающие приливные воздействия Лу- ны и Солнца, а также влияние смещения полюса Земли и притяжения изменяющихся атмосферных масс [Arnautov, 2005]. Вертикальными штриховыми линиями на рис. 7 обозначены моменты близлежащих к пункту наблюдений землетрясений (29.06.1995 г., $\mathrm{M}=5.6, \mathrm{~L}=67$ км от эпицентра до пункта «Талая»; 25.02.1999 г., $\mathrm{M}=5.8, \mathrm{~L}=86 \mathrm{кM} ; 17.09 .2003$ г., $\mathrm{M=5.3,}$ $\mathrm{L}=155$ км; 23.02.2005 г., $\mathrm{M=5.3,} \mathrm{L=160} \mathrm{км;} \mathrm{27.08.2008}$ г., $\mathrm{M}=6.3, \mathrm{~L}=25 \mathrm{kм})$.

За двадцатилетний (1992-2012 гг.) период наблюдений на пункте «Талая» зарегистрированы обратимые вариации силы тяжести. Амплитуда отклонений от начального значения достигала 25 мкгал при ошибке измерений от 0.5 до 2 мкгал. Дополнительные осложнения при проведении измерений вызваны периодической модернизацией приборного комплекса и изменением эффективной высоты гравиметра. Линейная составляющая вариаций на периодах 1992-2008 гг. и 2000-2008 гг. равна 1 мкгал/год. Зарегистрировано значимое косейсмическое уменьшение значения силы тяжести при Култукском землетрясении 27.08. 2008 г.

Приливный анализ вариаций водного уровня в скважине, пробуренной в скальных породах, показал присутствие зоны линейной трещиноватости по доли- 


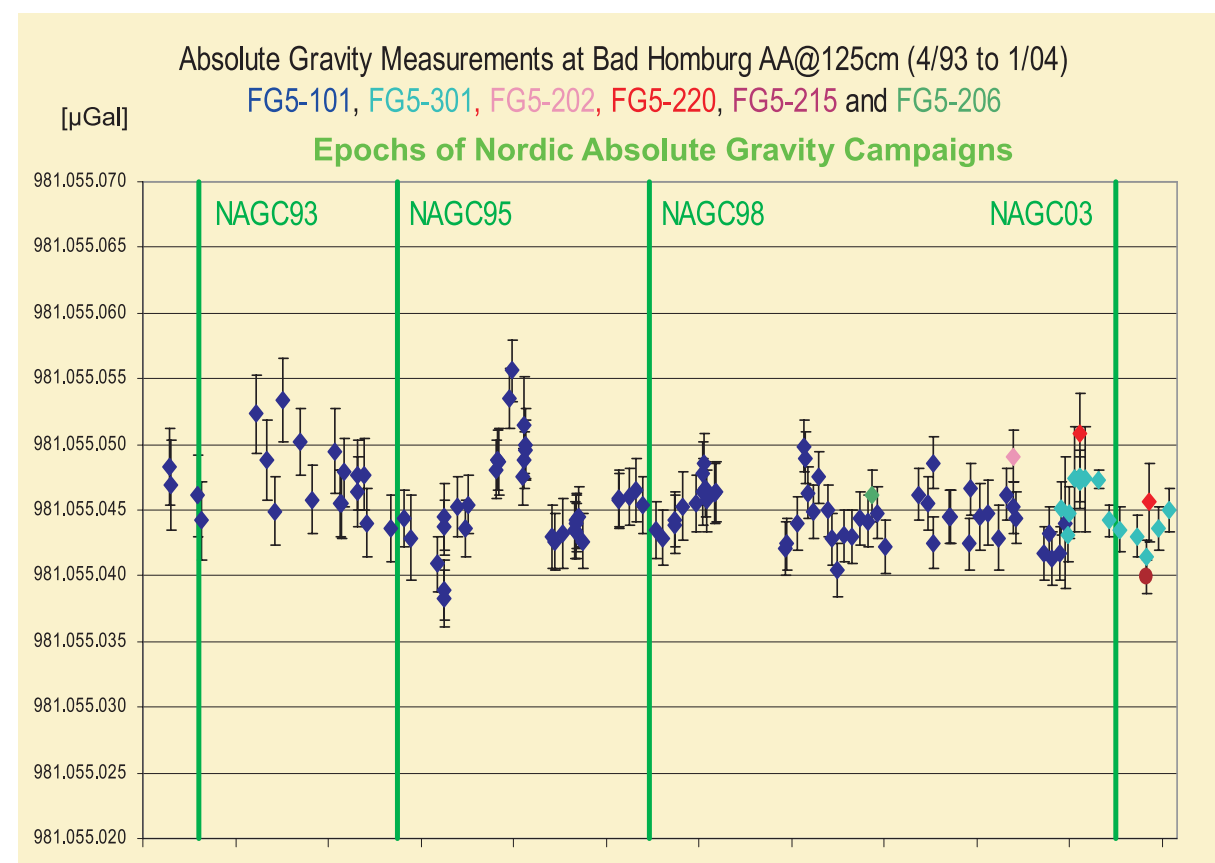

Рис. 5. Геофизическая обсерватория (Bad Homburg), Германия.

Вариации значения силы тяжести в микрогалах за период 1993-2004 гг. (результаты измерений абсолютными гравиметрами типа FG-Фарелла).

Fig. 5. The Geophysical Observatory in Bad Homburg, Germany.

Variations in gravity values for the period from 1993 to 2004 (microgals per year) (measurements by FG-Farell absolute gravimeters).

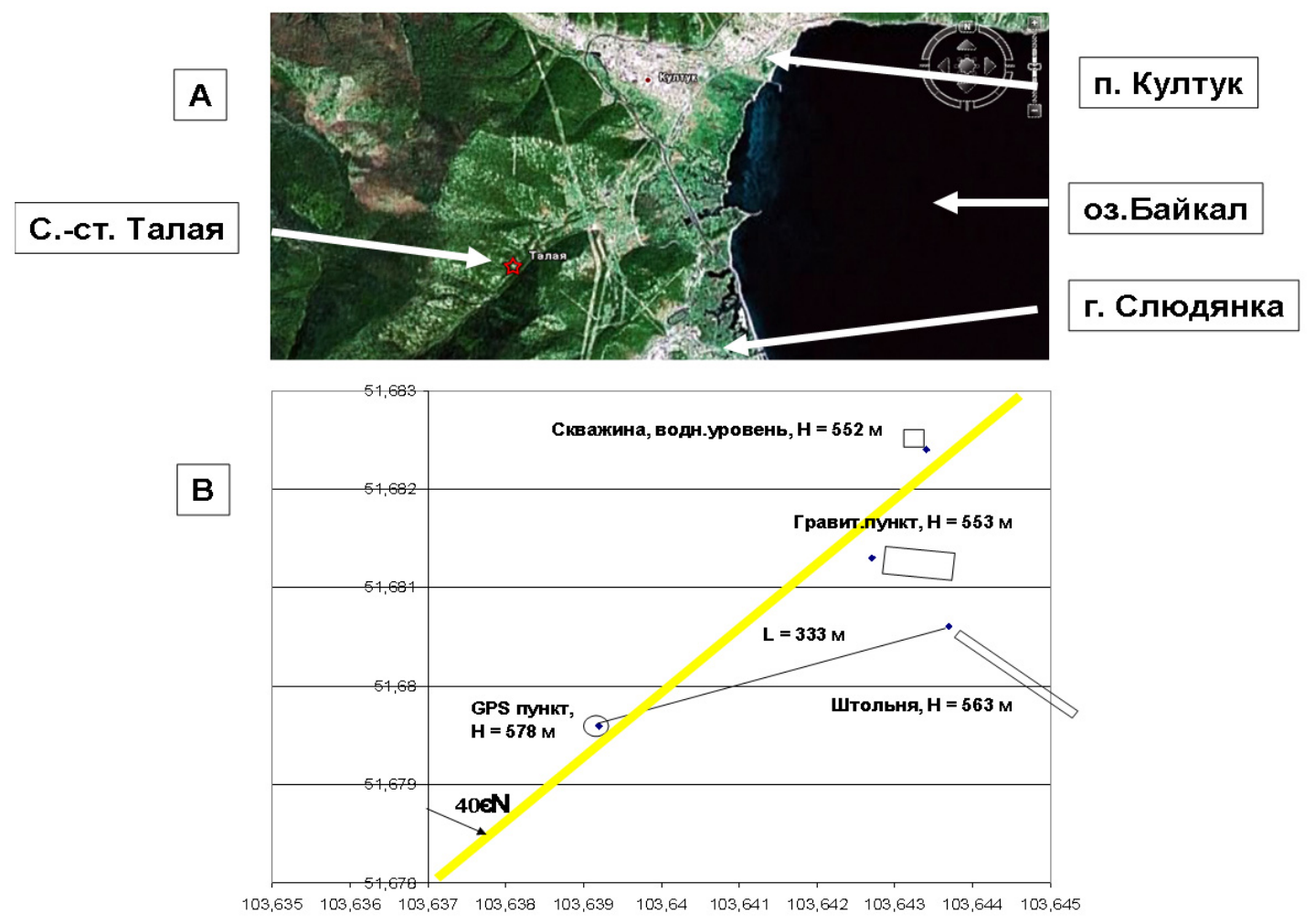

Рис. 6. Положение обсерватории Талая и размещение пунктов измерений на обсерватории.

Fig. 6. Locations of the Talaya Observatory and measurement sites in the observatory’s area. 


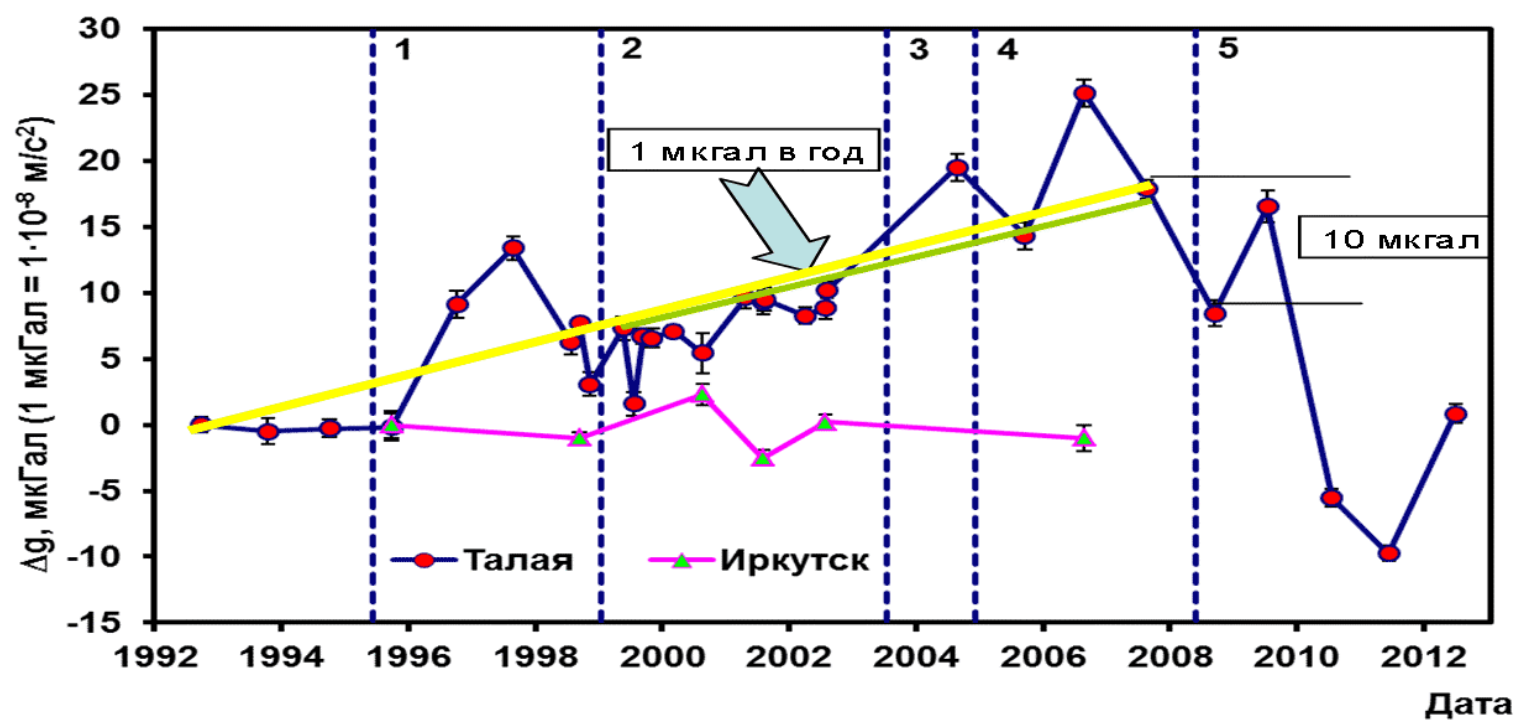

\section{Изменение силы тяжести, линейный тренд и аномальная часть связанная с деформацией земной коры}

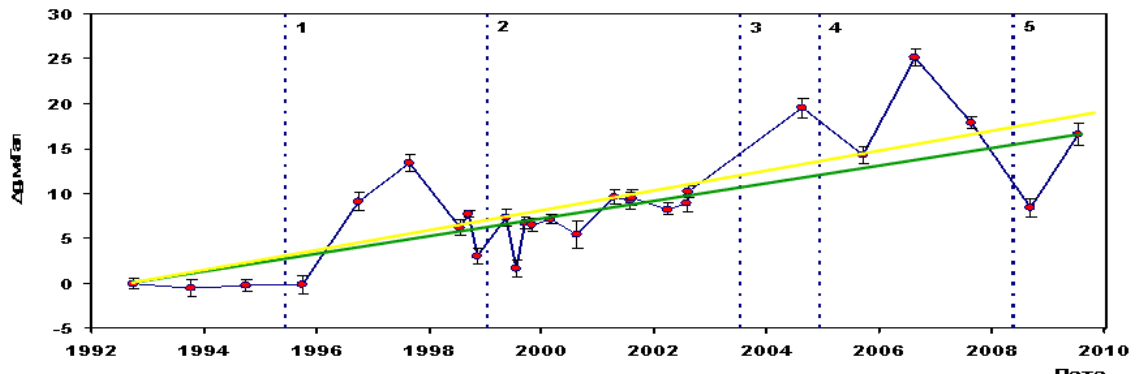

Землетрясения, $M>5, L<100 \mathrm{~km}$

$M=5.6 ; 29 / 06 / 1995$;

$51.71^{\circ} \mathrm{N}, 102.70^{\circ} \mathrm{E}$

67 км на запад

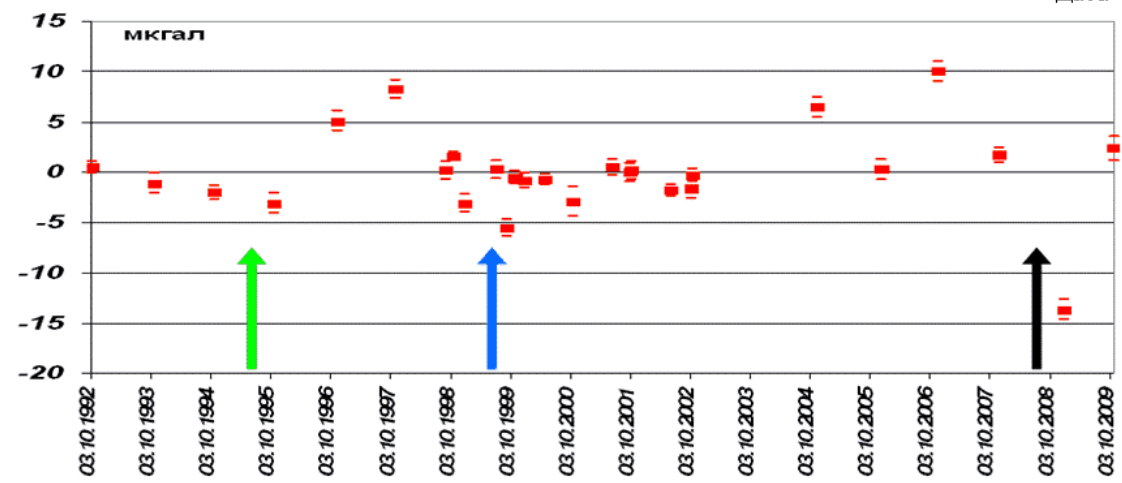

$M=5.8-5.1$;

25/02/1999- 31/05/2000;

$51.63-51.71^{\circ} \mathrm{N}$

104.89-104.84 ${ }^{\circ} \mathrm{E}$;

86 км на восток

$M=6.3 ; 27 / 8 / 2008$;

$51.61^{\circ} \mathrm{N}, 104.02^{\circ} \mathrm{E}$;

25 км на восток $E$

Рис. 7. Вариации силы тяжести в микрогалах, время - годы.

Вверху - изменения на пунктах «Талая» (1992-2012 гг.) и «Иркутск» (1995-2006 гг.), желтая линия - линейный тренд 1992-2007 гг., зеленая линия - линейный тренд 1999-2007 гг. Внизу - вариации на пункте «Талая» - линейный тренд на периодах 1992-2005 и 19922009, изменения значения силы тяжести при снятом линейном тренде (1 мкгал/год), стрелками показаны моменты землетрясений.

Fig. 7. Variations of gravity (microgal) with time (year).

Top - changes at the Talya (1992-2012) and Irkutsk sites (1995-2006); the yellow line shows the linear trend for the period from 1992 to 2007; the green line shows the linear trend for the period from 1999 to 2007. Bottom - variations at the Talaya site - the linear trend for periods from 1992 to 2005 and from 1992 to 2009; changes of gravity values for the linear trend (1 microgal per year); arrows show time of earthquakes. 

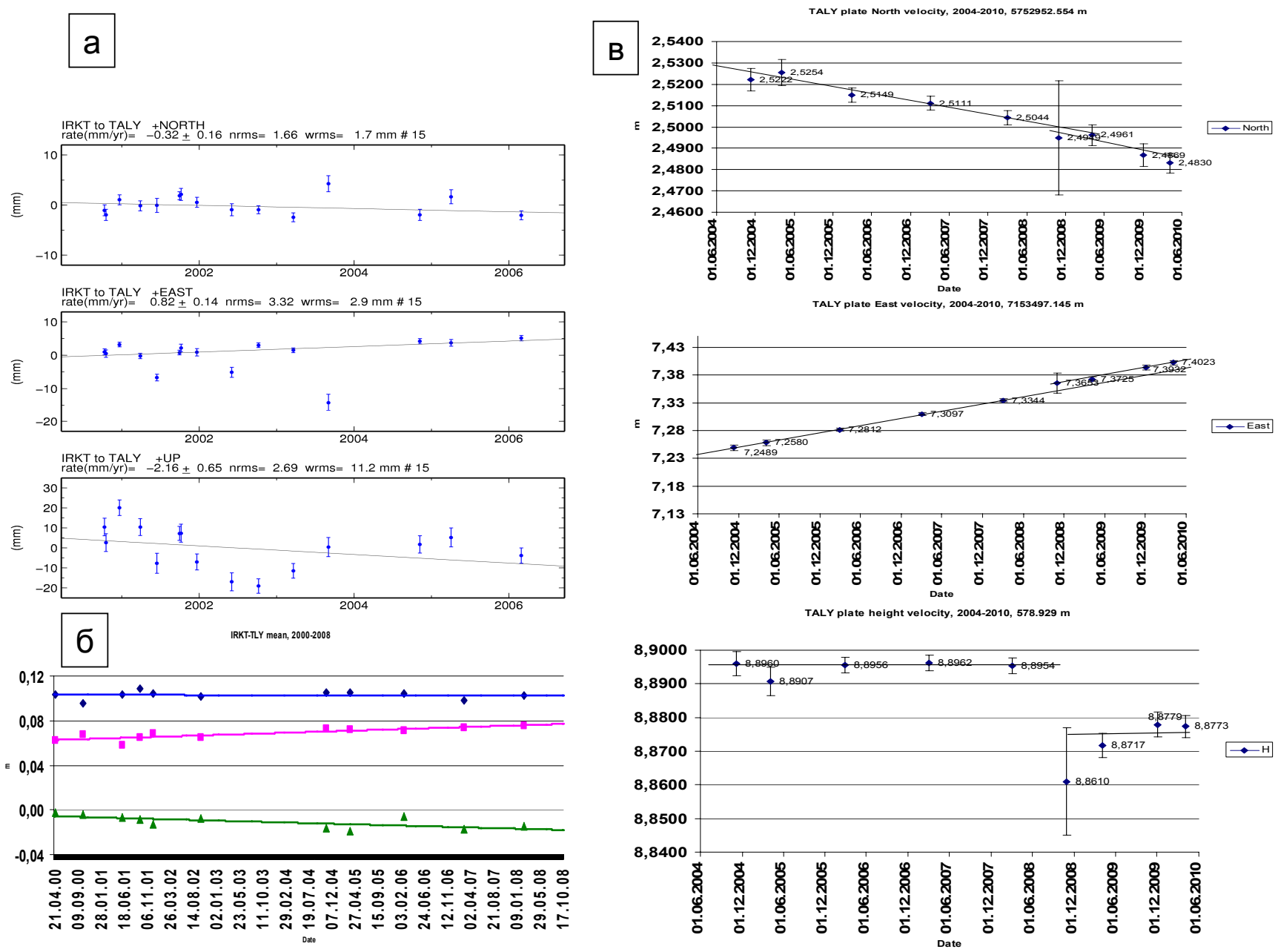

Рис. 8. Скорости смещения пункта «Талая» (на каждом графике сверху вниз: С-Ю, В-3, вертикальная; + на север, на восток и вверх).

(a) и (б) относительно пункта «Иркутск» (рис. 3). $a$ - результаты обработки данных по программе GAMIT/GLOBK эпоха 2000-2006 гг.: $\mathrm{V}_{\mathrm{n}}=-0.32 \pm 0.16$ мм, $\mathrm{V}_{\mathrm{e}}=+0.82 \pm 0.14$ мм и $\mathrm{V}_{\mathrm{h}}=-2.16 \pm 0.65$ мм/год. Шкала в мм. б - \pm результаты обработки данных по программе GPSurvey, эпоха весна 2000 г. - весна 2008 г.: $\mathrm{V}_{\mathrm{n}}=-0.1$ мм в год, $\mathrm{V}_{\mathrm{e}}=+1.5$ мм в год и $\mathrm{V}_{\mathrm{h}}=-2.8$ мм в год. Шкала в метрах. в - косейсмический скачок смещений, период осень 2004 г. - весна 2010 г.: $\mathrm{V}_{\mathrm{n}}=-2 \pm 2$ мм (на юг), $\mathrm{V}_{\mathrm{e}}=10 \pm 2$ мм на восток и опускание $20 \pm 5$ мм. Решение геоцентрическое - относительно центра масс Земли. Шкала в метрах.

Fig. 8. Velocities of displacement at the Talaya site (in each curve, from top to bottom: N-S, E-W, vertical, + to the north, to the east and upward).

(a) and (б) with reference to Irkutsk (Fig. 3). $a$ - results of data processing by GAMIT/GLOBK software for the period from 2000 to 2006 : $\mathrm{V}_{\mathrm{n}}=-0.32 \pm 0.16 \mathrm{~mm}$ per year, $\mathrm{V}_{\mathrm{e}}=+0.82 \pm 0.14 \mathrm{~mm}$ per year, and $\mathrm{V}_{\mathrm{h}}=-2.16 \pm 0.65 \mathrm{~mm}$ per year. The scale is given in millimetres. $\sigma-$ results of data processing by GPSurvey software for the period from the spring of 2000 to the spring of $2008: V_{n}=-0.1 \mathrm{~mm}$ per year, $\mathrm{V}_{\mathrm{e}}=+1.5 \mathrm{~mm}$ per year, and $V_{h}=-2.8 \mathrm{~mm}$ per year. The scale is given in metres. 8 - Coseismic displacement discontinuity for the period from the autumn of 2004 to the spring of 2010: $V_{n}=-2 \pm 2 \mathrm{~mm}$ (to the south), $V_{e}=10 \pm 2 \mathrm{~mm}$ in the east and the lower $20 \pm 5 \mathrm{~mm}$. The geocentric solution is given with reference to the Earth's mass centre; the scale is given in metres.

не. Ежедневный опрос значения водного уровня в скважине № 1608 на станции «Талая» проводился с 1993 г. по 2003 г., цифровая запись уровня начата в 2005 г. [Timofeev et al., 2012a].

Отметим, что уровень находится около поверхности (высота патрубка 0.8 м), а его вариации связаны с летними осадками и сезонными эффектами. В то же время здесь отсутствует резкое весеннее изменение уровня, возможно, вследствие большой глубины про- мерзания грунтов. Из анализа многолетних изменений можно уверенно говорить лишь о сезонных вариациях, вызванных обильными летними дождями (июль, август) и о периодических 10-12-летних вариациях, связанных с климатическими циклами [Timofeev et al., 2012a].

Анализ показал отсутствие корреляции полученных изменений силы тяжести с вариациями уровня воды в скважине, а в результате специальных исследований 

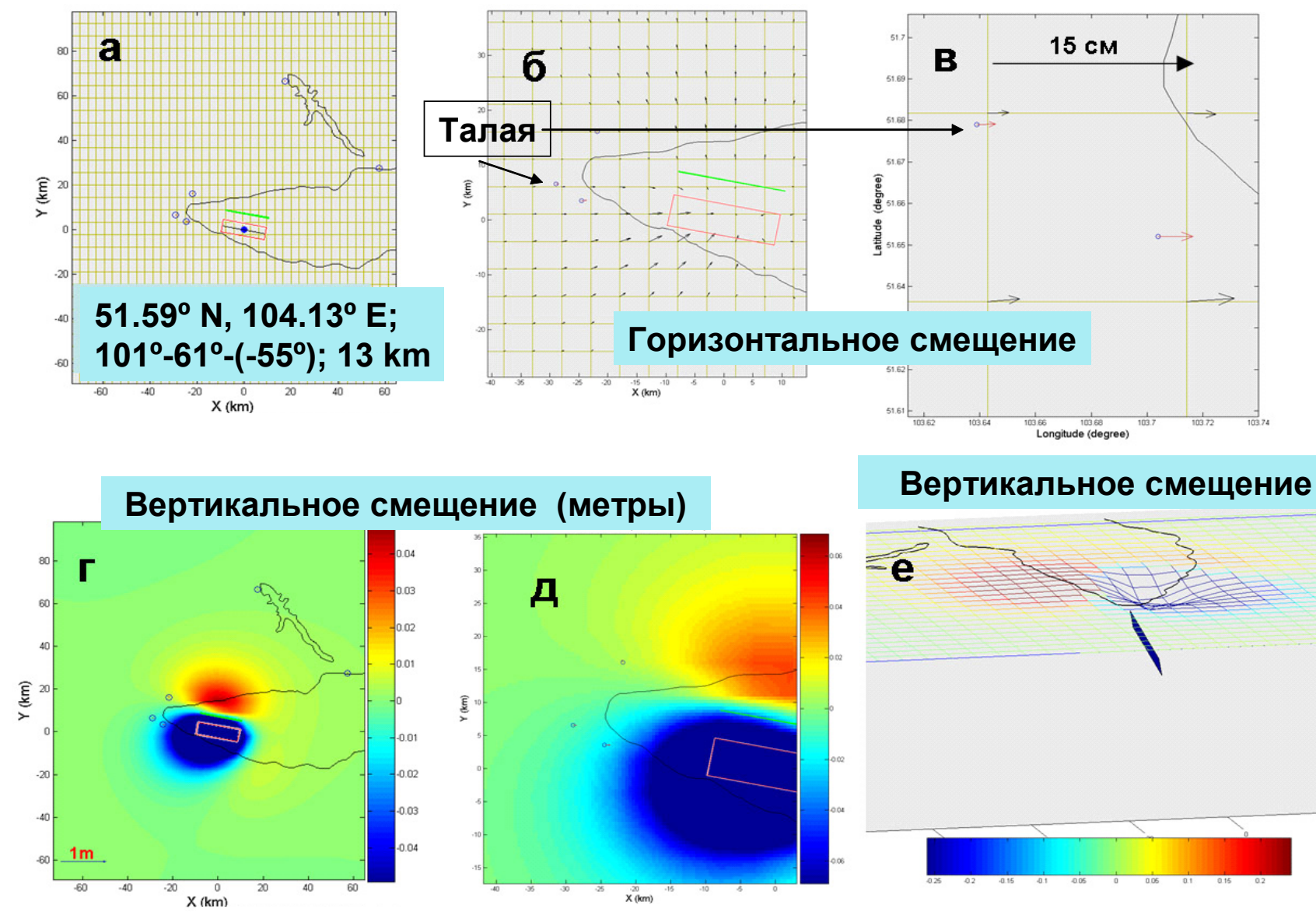

Рис. 9. Результаты моделирования косейсмических смещений при Култукском землетрясении 2008 г. (M=6.3) [Toda et al., 2009].

Fig. 9. Coseismic displacement modeling results for the Kultuk earthquake (2008, M=6.3) [Toda et al., 2009].

(2001-2003 гг.) определена амплитуда сезонных изменений g, она достигает 3 мкгал. Снятие линейной составляющей с графика силы тяжести проявило эффекты в эпохи близких землетрясений $(\mathrm{M}=5.6,29.06 .1995$ г., $\mathrm{L}=67$ км; $\mathrm{M}=5.8,25.02 .1999$ г., $\mathrm{L}=86$ км; $\mathrm{M}=6.3$, 27.08.2008 г., L=25 км), при этом наиболее сильный эффект зарегистрирован при Култукском землетрясении 2008 г. Значимые изменения g зарегистрированы в периоды землетрясений с магнитудой больше 5.5 на расстояниях менее 90 км от станции (рис. 7).

Вариации 3D смещений пункта за период 20002010 гг., полученные с использованием программ GPSurvey и GAMIT/GLOBK [King, Bock, 2006; Herring et al., 2006], показаны на рис. 8.

Горизонтальные скорости согласуются с результатами, полученными по данным Байкальской сети за период 1994-2007 гг. [San'kov et al., 2009; Lukhnev et al., 2010]. Для периода 2000-2008 гг. перед Култукским землетрясением приведены решения для скоростей относительно пункта «Иркутск», расположенного на Сибирской платформе. Значения по компонентам составили: $\mathrm{Vn}=-0.1 \ldots-0.3$ мм/год, $\mathrm{Ve}=+0.8 \ldots+1.5$ мм/год, $\mathrm{Vv}=-2.1 \ldots-2.8$ мм/год. Составляющая вертикальной скорости может быть связана с рифтовыми процессами региона. Для периода 2004-2010 гг. приведено геоцентрическое решение. Здесь хорошо проявились косейсмические смещения для всех трех компонент. На периоде весна 2008 г. - весна 2010 г. изменения составили соответственно: $\mathrm{N}=-2 \pm 2$ мм, $\mathrm{E}=$

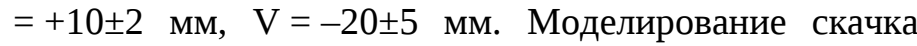
смещений проводилось с использованием сейсмологических данных, полученных Байкальским филиалом Геофизической службы СО РАН. На рис. 9 приведены результаты моделирования. В целом модели, построенные по данным сейсмологии и космической геодезии, соответствуют друг другу.

Рассматривая данные измерений в период 20092012 гг., следует отметить, что вертикальные смещения продолжали изменяться (рис. 10). Вариации продолжались и в значениях силы тяжести (см. рис. 7). Обратимся к комплексной интерпретации данных гравиметрии и космической геодезии.

Рассмотрим соотношения, связывающие изменения силы тяжести, вариаций высоты и плотности горных 
TALY Up Offset $578.929 \mathrm{~m}$

$\operatorname{rate}(\mathrm{mm} / \mathrm{yr})=-4.21 \pm 0.35 \mathrm{nrms}=3.88 \mathrm{wrms}=25.5 \mathrm{~mm} \# 25$

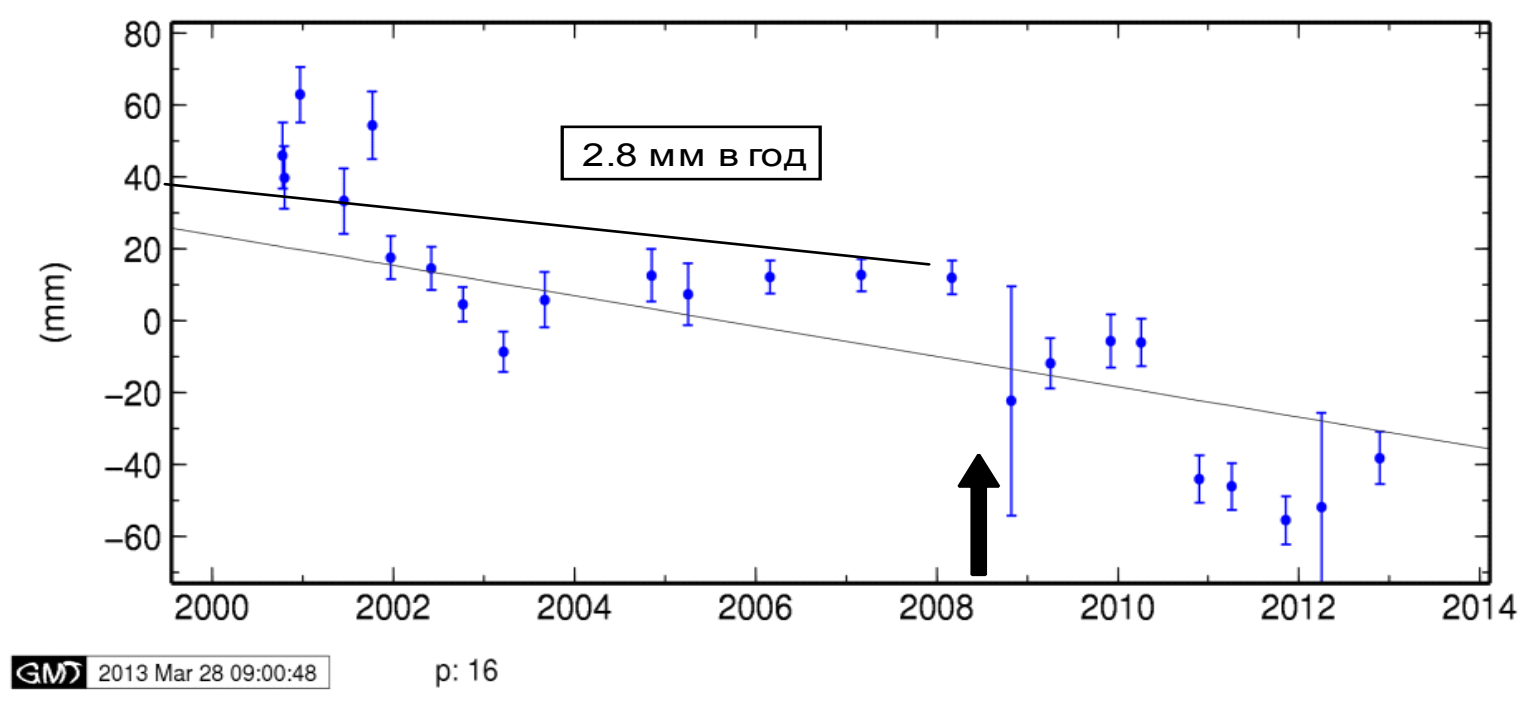

Рис. 10. Вертикальное смещение пункта «Талая», мм, в период 2000-2012 гг.

Результаты обработки данных по программе GAMIT/GLOBK, геоцентрическое решение, шкала в мм. Скорость смещения до Култукского землетрясения -2.8 мм/год. Далее косейсмическое смещение в 20 мм, в конце 2010 г. зарегистрирован постсейсмический скачок до 40 мм, и в конце 2012 г. начинается обратное движение.

Fig. 10. Vertical displacement (in millimetres) of the Talaya site in the period from 2000 to 2012.

Results of data processing by GAMIT/GLOBK software; the geocentric solution; the scale is given in millimetres. Prior to the Kultuk earthquake, the displacement velocity amounted to $2.8 \mathrm{~mm}$ per year. Afterwards the coseismic displacement of $20 \mathrm{~mm}$ occurred; in late 2010, the post-seismic discontinuity up to $40 \mathrm{~mm}$ occurred, and at the end of 2012, the reverse movement commenced.

пород. Для воздействий, охватывающих часть земной коры с линейными размерами в 100-200 км, идеализируя, их можно свести к трем положениям.

1. При плотности $\rho=$ const.

Связь вариаций g и высоты Z без учета деформации среды можно описать как

$\Delta \mathrm{g}(\mathrm{t})=\gamma \cdot \Delta \mathrm{Z}(\mathrm{t})$,

где $\gamma$ - вертикальный градиент g и $\Delta \mathrm{Z}(\mathrm{t})$ - изменение высоты пункта.

2. При высоте $\mathrm{Z}=$ const.

Связь вариаций g и изменений плотности $\rho$, вызванных деформацией среды. Можно использовать формулу для притяжения бесконечного плоского слоя [Tsuboi, 1982]:

$\Delta \mathrm{g}=2 \pi \cdot k \cdot \Delta \rho \cdot d=2 \pi \cdot k \cdot \Delta \varepsilon \cdot \rho \cdot d$,

где $\mathrm{k}=6.67 \cdot 10^{-8} \mathrm{~cm}^{3} /$ гс $^{2}$ - гравитационная постоянная, $d$ - толщина деформированного слоя земной коры, $\rho=2.67$ г/см ${ }^{3}-$ средняя плотность земной коры, $\Delta \rho-$ изменение $\rho$ из-за объемной деформации $\Delta \varepsilon$ земной коры.

3. Связь $\Delta \mathrm{g}$ и изменений смещений и деформации записывается как [Sasagawa, Zumberge, 1991]:
$\Delta g=[\gamma+2 \pi k \rho(1-v) / v] \Delta z$

где $\mathrm{k}$ - гравитационная постоянная, $\rho$ - плотность, $\mathrm{v}$ коэффициент Пуассона, $\Delta \mathrm{z}$ - изменение высоты, $\mathrm{\gamma}-$ вертикальный градиент.

Нормальное значение вертикального градиента составляет 308 мкгал на метр. Экспериментальное значение, полученное по данным измерений гравиметром Лакоста-Ромберга (LCR G 402) на пункте «Талая» 180 мкгал на метр. Такое значение обусловлено узкой горной долиной и расположением постамента в подвале на 2.5 м ниже земной поверхности. При нормальном градиенте получаем эффект +3.0 мкгал при опускании поверхности на 1 см (+1 мкгал $\approx-3$ мм), используя экспериментальное определение, оцениваем эффект в +1.8 мкгал при опускании поверхности на 1 см.

Рассматривая соотношения вертикального опускания пункта «Талая» в период 2000-2008 гг. и значение силы тяжести, получаем качественное соответствие. Скорость опускания до -2.8 мм/год и увеличение значения силы тяжести +1 мкгал/год ближе к нормальному значению вертикального градиента.

Нормальные значения параметров составляют для средней плотности земной коры $\rho=2.67$ г/см ${ }^{3}$, для коэффициента Пуассона $v=0.25$. Горные породы - архейские мраморы, которыми сложена долина р. Талая, 
Фазовое запаздывание в градусах, период 1995-2012 гг.

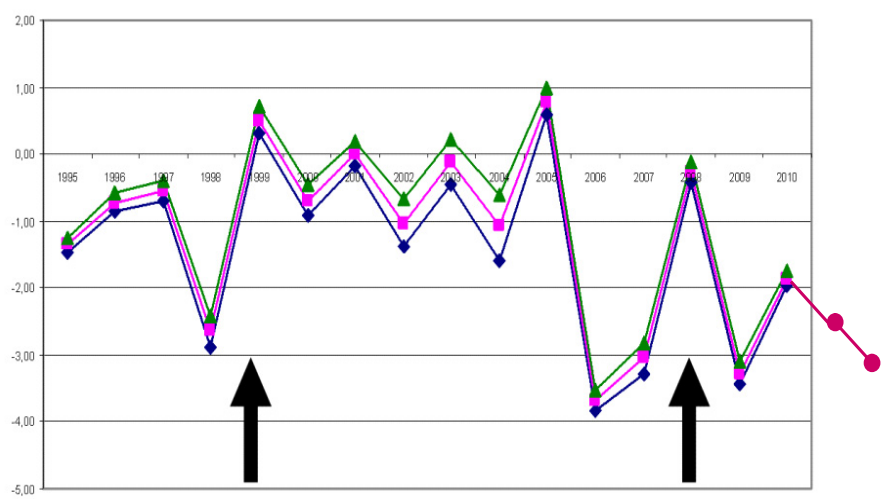

$b$

Изменение объёмной деформации (х106), период 1989-2012 гг.

Рис. 11. Результаты обработки данных деформографических измерений.

$a$ - вариации фазового приливного запаздывания в градусах, период наблюдений 1995-2012 гг.; $b$ - изменение значения объемной деформации за период 1989-2012 гг. Стрелками показаны периоды землетрясений [Timofeev et al., 2012b].

Fig. 11. Results of deformographic measurement data processing.

$a$ - variations of phased tidal lag in degrees for the observation period from 1995 to 2012; $b$ - changes of the volume deformation for the period from 1989 to 2012. Arrows show time of earthquakes [Timofeev et al., 2012b].

были исследованы лабораторно. На образце керна, извлеченном из 100-метровой скважины, получены значения коэффициента Пуассона $v=0.17$ и плотности $\rho=2.87 \Gamma^{\cdot} \mathrm{cm}^{-3}$. По соотношению (5) получаем сходные оценки. Так, при изменении деформации $\Delta \varepsilon=1 \cdot 10^{-6}$ и мощности слоя в 1 км эффект составит 0.12 мкгал, при мощности 3 км - 0.36 мкгал, при мощности 10 км - 1.2 мкгал, при мощности 30 км - 3.6 мкгал. Эффект положителен при сжатии, при растяжении отрицателен.

Эти соотношения (5) соответствуют периодам локальных землетрясений (см. рис. 7). Путем исключения линейной составляющей получены аномальные значения до и после землетрясений, случившихся в окрестностях станции (до 90 км), они достигают 5-10 мкгал. Согласно зарегистрированным деформографами данным (рис. 11), на поверхности деформации достигают $\Delta \varepsilon=2 \cdot 10^{-6}-3 \cdot 10^{-6}$ [Timofeev et al., 2012b]. При мощности слоя земной коры 25 км эффект, согласно соотношению (5), составит 4.8-7.2 мкгал.

Для комплексного эффекта смещений и деформаций, используя соотношение (6), получаем при нормальных значениях вертикального градиента оценку +0.27 мкгал на +1 см вертикального смещения (опускание поверхности «-»). По данным, полученным экспериментально, оценка эффекта составит +4.07 мкгал при смещении +1 см. Последние оценки с учетом ошибок измерений соответствуют косейсмическому эффекту Култукского землетрясения (рис. 12) и результатам моделирования по данным сейсмологии (см. рис. 9). Процесс опускания земной поверхности при Култукском землетрясении продолжался с 2008 г. по 2012 г., проходил в несколько этапов и зарегистрирован методами космической геодезии и абсолютной гравиметрии. Особенности процесса и его продолжительность, возможно, свидетельствуют о включении флюидов в постсейсмический процесс. Этот вопрос требует дополнительных многолетних наблюдений.

\section{4. ЗАКЛЮЧЕНИЕ}

Результаты работы можно свести к нескольким выводам. Экспериментальные оценки стабильности значения силы тяжести и высоты по данным трех обсерваторий ограничивают изменение радиуса Земли значением $10^{-10}$ в год от нормального значения. Эти оценки можно использовать для тестирования тектонических гипотез.

Линейная составляющая вариации силы тяжести на станции Талая соответствует изменениям высоты пункта. Коэффициент корреляции близок к нормальному значению вертикального градиента силы тяжести.

Косейсмические вариации силы тяжести на этом пункте в эпоху Култукского землетрясения 2008 г. вызваны комплексным эффектом изменения высоты пункта и деформации земной коры.

Процесс опускания земной поверхности при Кул- 

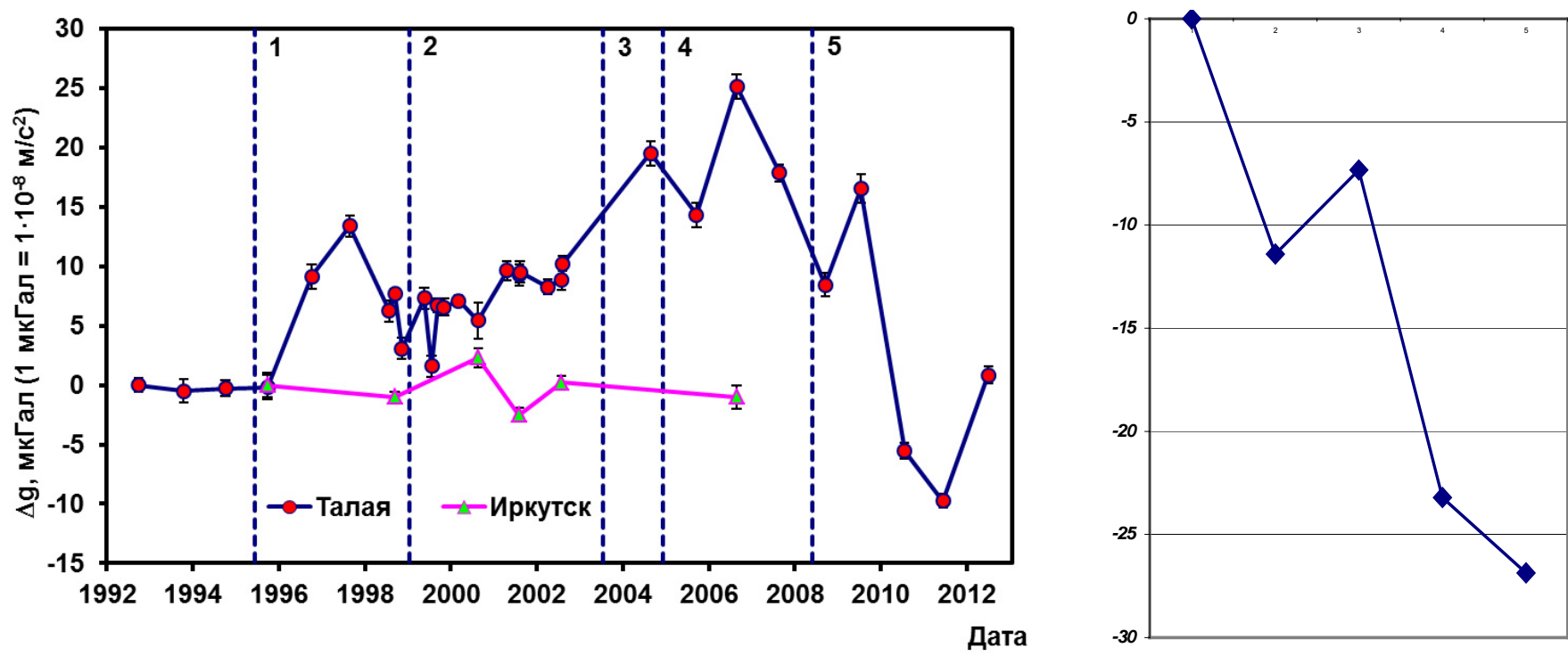

Рис. 12. Вариации силы тяжести, зарегистрированные абсолютным гравиметром и пересчитанные из вертикальных смещений.

Fig. 12. Gravity variations recorded by an absolute gravity meter and those calculated from vertical displacements.

тукском землетрясении продолжался три года и проходил в несколько этапов. Природу этого процесса, влияние флюидов в земной коре [Fialko, 2004] и асейсмического скольжения можно рассматривать через несколько лет дополнительных наблюдений.

Вариации силы тяжести в периоды региональных землетрясений с магнитудой больше 5.5, произошедших на расстояниях менее 90 км от станции, обуслов- лены изменением деформируемого состояния земной коры. Для объяснения гравитационного эффекта изменения деформации должны составить величину $\Delta \varepsilon=2 \cdot 10^{-6}-3 \cdot 10^{-6}$ и охватывают слой мощностью 20 км.

Работа была выполнена в рамках проектов Президиума РАН № 4.1, МИП СО РАН № 76, ОНЗ РАН № 6-2.

\section{5. ЛИТЕРАТУРА}

Altamimi Z., Collilieux X., Legrand J., Garayt B., Boucher C., 2007. ITRF2005: A new release of the International Terrestrial Reference Frame based on time series of station positions and Earth Orientation Parameters. Journal of Geophysical Research 112 (B9), B09401. http://dx.doi.org/10.1029/2007JB004949.

Arnautov G.P., 2005. Results of international metrological comparison of absolute laser ballistic gravimeters. Avtometria 41 (1), 126-136 (in Russian) [Арнаутов Г.П. Результаты международных метрологических сравнений абсолютных лазерных баллистических гравиметров // Автометрия. 2005. Т. 41. № 1. С. 126-136].

Arnautov G.P., Kalish E.N., Smirnov M.G., Stus' Yu.F., Tarasyuk V.G., 1994. Laser ballistic gravimeter GABL-M and gravity observation results. Avtometria 3, 3-11 (in Russian) [Арнаутов Г.П., Калиш Е.Н., Смирнов М.Г., Стусь Ю.Ф., Тарасюк В.Г. Лазерный баллистический гравиметр ГАБЛ-М и результаты наблюдений силы тяжести // Автометрия. 1994. № 3. С. 3-11].

Ducarme B., Timofeev V.Yu., Everaerts M., Gornov P.Y., Parovishnii V.A., van Ruymbeke M., 2008. A Trans-Siberian tidal gravity profile (TSP) for the validation of the ocean tides loading corrections. Journal of Geodynamics 45 (2-3), 73-82. http://dx.doi.org/10.1016/j.jog.2007.07.001.

Elhiny M.W., Taylor S.R., Stevenson D.J., 1978. Limits to the expansion of Earth, Moon, Mars and Mercury and to change in the gravitational constant. Nature 271 (5643), 316-321. http://dx.doi.org/10.1038/271316a0.

Fialko Y., 2004. Evidence of fluid-filled upper crust from observations of postseismic deformation due to the 1992 Mw7.3 Landers earthquake. Journal of Geophysical Research 109 (B8), B08401. http://dx.doi.org/10.1029/2004JB002985.

Herring T.A., King R.W., McClusky S.C., 2006. Globan Kalman Filter VLBI and GPS Analysis Program. Release 10.3. Department of Earth, Atmospheric, and Planetary Sciences, Massachussetts Institute of Technology, 87 p.

Hinderer J., Crossley D., 2006. NEWSLETTER 17, 5 June 2006, 2-12.

Kaftan V.I., Tsyba E.N., 2009. Assessment of changes in semi-axes of the Earth’s geometric ellipsoid from results of satellite 
V.Yu. Timofeev et al.: Gravity variations and recent geodynamics...

observations of the global geodetic networks. Izvestia VUSov, Geodeziya i aerofotos'emka 1, 33-40 (in Russian) [Kaфтан В.И., Цыба Е.Н. Оценка изменений полуосей земного геометрического эллипсоида по результатам спутниковых наблюдений в глобальной геодезической сети // Известия ВУЗов, Геодезия и аэрофотосъемка. 2009. № 1. С. 33-40].

King R.W., Bock Y., 2006. Documentation for the GAMIT GPS. Analysis software. Release 10.3. Cambridge, Massachussetts Institute of Technology, $182 \mathrm{p}$.

Kolomiets A.G., Gerasimenko M.D., Il'nitskaya A.V., 2010. Problems of seismicity and modern geodynamics of the Far East and East Siberia. In: Reports of the Scientific Symposium, 1-4 June 2010, Khabarovsk. ITIG, Khabarovsk, p. 87-88 (in Russian) [Коломиец А.Г., Герасименко М.Д., Ильницкая А.В. Проблемы сейсмичности и современной геодинамики Дальнего Востока и Восточной Сибири // Доклады научного симпозиума 1-4 июня 2010 г., Хабаровск. Хабаровск: ИТИГ, С. 87-88.

Kukol Z., 1987. Velocities of Geological Processes. Mir, Moscow, 246 p. (in Russian) [Кукол 3. Скорость геологических процессов. М.: Мир, 1987. 246 с.].

Lukhnev A.V., San'kov V.A., Miroshnichenko A.I., Ashurkov S.V., Calais E., 2010. GPS rotation and strain rates in the BaikalMongolia region. Russian Geology and Geophysics 51 (7), 1006-1017. http://dx.doi.org/10.1016/j.rgg.2010.06.006.

Robertson L., Francis O., van Dam T.M., Faller J., Ruess D., Delinte J.-M., Vitushkin L., Liard J., Gagnon C., Guang G.Y., Da Lun H., Yuan F.Y., Yi X.J., Jeffries G., Hopevell H., Edge R., Robinson I., Kibbe B., Makinen J., Hinderer J., Amalvict V., Luck B., Wilmes H., Rehren F., Schmidt K., Schnull M., Cerutti G., Germmak A., Zabek Z., Pachuta A., Arnautov G., Kalish E., Stus Yu., Stizza D., Friderich J., Chartier J.-M., Marson I., 2001. Results from the fifth international comparison of absolute gravimeters, ICAG'97. Metrologia 38 (1), 71-78. http://dx.doi.org/10.1088/0026-1394/38/1/6.

San'kov V.A., Lukhnev A.V., Miroshnichenko A.I., Ashurkov S.V., Byzov L.M., Dembelov M.G., Calais E., Deverchère J., 2009. Extension in the Baikal rift: Present-Day kinematics of passive rifting. Doklady Earth Sciences 425 (2), 205-209. http://dx.doi.org/10.1134/S1028334X09020056.

Sasagawa S., Zumberge M.A., 1991. Absolute gravity measurements in California, 1984-1989. Journal of Geophysical Research 96 (B2), 2501-2513. http://dx.doi.org/10.1029/90JB02283.

Timofeev V.Yu., Ardyukov D.G., Boiko E.V., Gribanova E.I., Semibalamut V.M., Timofeev A.V., Yaroshevich A.V., 2012 b. Strain and displacement rates during a large earthquake in the South Baikal region. Russian Geology and Geophysics 53 (8), 798-816. http://dx.doi.org/10.1016/j.rgg.2012.06.007.

Timofeev V.Yu., Ardyukov D.G., Boiko E.V., Timofeev A.V., Yaroshevich A.V., Gornov P.Yu., 2012a. Estimation of coseismic deformation, poroelasticity, and fracturing of rocks from the data on water level in a borehole. Izvestiya, Physics of the Solid Earth 48 (7-8), 640-652. http://dx.doi.org/10.1134/S1069351312060067.

Toda S., Ross S., Sevilgen V., Lin J., 2009. Coulomb 3. Graphic-rich deformation \& stress-change software for earthquake, Tectonic, and Volcano Research and Teaching - User Guide. Available from: http://pubs.usgs.gov/of/2011/1060 (last accessed 30.04.2013).

Tsuboi T., 1982. The Earth’s Gravity Field. Mir, Moscow, 286 p. (in Russian) [Цубои Т. Гравитационное поле Земли. М.: Мир, 1982. 286 с.].

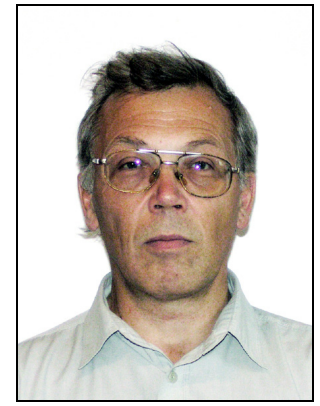

Тимофеев Владимир Юрьевич, докт. физ.-мат. наук, заведующий лабораторией

Институт нефтегазовой геологии и геофизики им. А.А. Трофимука СО РАН

630090, Новосибирск, пр. Академика Коптюга, 3, Россия

Тел.: (383)3356442, \ e-mail: timofeevvy@ipgg.nsc.ru

Timofeev, Vladimir Yu., Doctor of Physics and Mathematics, Head of Laboratory

A.A. Trofimuk Institute of Petroleum Geology and Geophysics, Siberian Branch of RAS

3 Akademika Koptyuga Prosp., Novosibirsk 630090, Russia

Tel.: (383)3356442; $₫$ e-mail: timofeevvy@ipgg.nsc.ru

Калиш Евгений Николаевич, канд. физ.-мат. наук, с.н.с.

Институт автоматики и электрометрии СО РАН

630090, Новосибирск, пр. Академика Коптюга, 1, Россия

Тел.: (383)3332596, e-mail: kalish@iae.nsk.su

Kalish, Evgeniy N., Candidate of Physics and Mathematics, Senior Researcher

Institute of Automation and Electrometry, Siberian Branch of RAS

1 Akademika Koptyuga Prosp., Novosibirsk 630090, Russia

Tel.: (383)3332596; e-mail: kalish@iae.nsk.su 
Стусь Юрий Фёдорович, канд. техн. наук, с.н.с.

Институт автоматики и электрометрии СО РАН

630090, Новосибирск, пр. Академика Коптюга, 1, Россия

Тел.: (383)3332596, e-mail: stus@iae.nsk.su

Stus', Yuri F., Candidate of Technical Sciences, Senior Researcher Institute of Automation and Electrometry, Siberian Branch of RAS

1 Akademika Koptyuga Prosp., Novosibirsk 630090, Russia

Tel.: (383)3332596; e-mail: stus@iae.nsk.su

\section{Ардюков Дмитрий Геннадьевич, с.н.с.}

Институт нефтегазовой геологии и геофизики им. А.А. Трофимука СО РАН

630090, Новосибирск, пр. Академика Коптюга, 3, Россия

Тел.: (383)3356442, e-mail: ardyukovdg@ipgg.nsc.ru

Ardyukov, Dmitriy G., Senior Researcher

A.A. Trofimuk Institute of Petroleum Geology and Geophysics, Siberian Branch of RAS

3 Akademika Koptyuga Prosp., Novosibirsk 630090, Russia

Tel.: (383)3356442; e-mail: ardyukovdg@ipgg.nsc.ru

Арнаутов Геннадий Петрович, канд. техн. наук, в.н.с.

Институт автоматики и электрометрии СО РАН

630090, Новосибирск, пр. Академика Коптюга, 1, Россия

Тел.: (383)3307931; e-mail: arnautov@iae.nsk.su

Arnautov, Gennadiy P., Candidate of Technical Sciences, Lead Researcher

Institute of Automation and Electrometry, Siberian Branch of RAS

1 Akademika Koptyuga Prosp., Novosibirsk 630090, Russia

Tel.: (383)3307931; e-mail: arnautov@iae.nsk.su

Смирнов Михаил Георгиевич, ведущий инженер-конструктор

Институт автоматики и электрометрии СО РАН

630090, Новосибирск, пр. Академика Коптюга, 1, Россия

Тел.: (383)3332596; e-mail: smirnov.m.g@iae.nsk.su

Smirnov Mikhail G., Lead Design Engineer

Institute of Automation and Electrometry, Siberian Branch of RAS

1 Akademika Koptyuga Prosp., Novosibirsk 630090, Russia

Tel.: (383)3332596; e-mail: smirnov.m.g@iae.nsk.su

Тимофеев Антон Владимирович, инженер

Институт нефтегазовой геологии и геофизики им. А.А. Трофимука СО РАН

630090, Новосибирск, пр. Академика Коптюга, 3, Россия

Тел.: (383)3356442; e-mail: timofeevav@ipgg.nsc.ru

Timofeev, Anton V., Engineer

A.A. Trofimuk Institute of Petroleum Geology and Geophysics, Siberian Branch of RAS

3 Akademika Koptyuga Prosp., Novosibirsk 630090, Russia

Tel.: (383)3356442; e-mail: timofeevav@ipgg.nsc.ru

Носов Дмитрий Алексеевич, инженер-программист

Институт автоматики и электрометрии СО РАН

630090, Новосибирск, пр. Академика Коптюга, 1, Россия

Тел.: (383)3332596, e-mail: danossov@ngs.ru

Nosov, Dmitriy A., Software Engineer

Institute of Automation and Electrometry, Siberian Branch of RAS

1 Akademika Koptyuga Prosp., Novosibirsk 630090, Russia

Tel.: (383)3332596; e-mail: danossov@ngs.ru

Сизиков Игорь Сергеевич, инженер-конструктор

Институт автоматики и электрометрии СО РАН

630090, Новосибирск, пр. Академика Коптюга, 1, Россия

Тел.: (383)3332596, e-mail: sizikov.i.s@gmail.com

Sizikov, Igor S., Design Engineer

Institute of Automation and Electrometry, Siberian Branch of RAS

1 Akademika Koptyuga Prosp., Novosibirsk 630090, Russia

Tel.: (383)3332596; e-mail: sizikov.i.s@gmail.com 
V.Yu. Timofeev et al.: Gravity variations and recent geodynamics...

Бойко Елена Валерьевна, н.с.

Институт нефтегазовой геологии и геофизики им. А.А. Трофимука СО РАН

630090, Новосибирск, пр. Академика Коптюга, 3, Россия

Тел.: (383)3356442, e-mail: boykoev@ipgg.nsc.ru

Boiko, Elena V., Researcher

A.A. Trofimuk Institute of Petroleum Geology and Geophysics, Siberian Branch of RAS

3 Akademika Koptyuga Prosp., Novosibirsk 630090, Russia

Tel.: (383)3356442; e-mail: boykoev@ipgg.nsc.ru

Грибанова Екатерина Ивановна, н.с.

Сибирский филиал Геофизической службы СО РАН

630090, Новосибирск, пр. Академика Лаврентьева, 13-3

Gribanova, Ekaterina I., Researcher

Siberian Division of Geophysic Survey, Siberian Branch of RAS

13 Akademika Lavrentieva Prosp., Novosibirsk 630090, Russia 